Article

\title{
An Assessment of SEVIRI Imagery at Various Temporal Resolutions and the Effect on Accurate Dust Emission Mapping
}

\author{
Mark Hennen ${ }^{1}$, Kevin White ${ }^{2, *}$ (D) and Maria Shahgedanova ${ }^{2}$ \\ 1 ARGANS Ltd., 1 Davy Road, Plymouth Science Park, Derriford, Plymouth PL6 8BX, UK; \\ mark.hennen@hotmail.co.uk \\ 2 Department of Geography and Environmental Science, University of Reading, Whiteknights, \\ Reading RG6 6AB, UK; m.shahgedanova@reading.ac.uk \\ * Correspondence: k.h.white@reading.ac.uk
}

Received: 25 February 2019; Accepted: 9 April 2019; Published: 16 April 2019

\begin{abstract}
This paper evaluates the use of the 'Dust red/green/blue (RGB)' product derived from Spinning Enhanced Visible and Infrared Imager (SEVIRI) data at 15-min, 30-min, and 60-min temporal resolutions, for monitoring dust emissions in the Middle East. From January 2006 to December 2006, observations of dust emission point sources were recorded at each temporal resolution across the Middle East. Previous work has demonstrated that using SEVIRI data is a major improvement on other remote sensing methods for mapping dust sources in the Sahara, by enabling dust-storm observations through sequential images, back to the point of first emission. However, the highest temporal resolution available (15-min observations) produces 96 images per day, resulting in significantly higher data management requirements than data provided at 30-min and 60-min intervals. To optimize future research workflows, this paper investigates the effect of lowering the temporal resolution on the number and spatial distribution of observed dust emission events in the Middle East. The results show that the number of events observed reduced by $17 \%$ for 30 -min resolution and $50 \%$ for 60 -min resolution. These differences change seasonally, with the highest reduction observed in summer $(34 \%$ and $64 \%$ reduction, respectively).
\end{abstract}

Keywords: atmospheric dust; Meteosat Second Generation; SEVIRI; Middle East

\section{Introduction}

Satellite-derived data are now widely used for the detection of dust in the atmosphere. The spatial coverage offered from low earth polar or geostationary orbits far exceeds that by aircraft-mounted or ground-based sensors [1,2]. The variety of platforms and sensors used to monitor atmospheric dust has increased greatly in the last few decades, providing new insights into atmospheric dust emission processes [3], dust source locations [4], the global aerosol burden [5], and radiative effects [6].

Observation of dust at the source of emission is of key importance, as its physical, chemical, and optical characteristics vary between source regions, evolving throughout the life span of each dust plume and along its transportation route [7]. Accurate simulation of transportation routes requires knowledge of the location of dust sources. Knowledge of dust trajectories and properties are necessary to improve dust representation in weather and climate models and thus increase the accuracy of the estimation of the resulting radiative forcing [1]. At present, maps of atmospheric optical depth (AOD) are often used in these models as a proxy for the location of dust sources, but this results in errors because high AOD values are a product of both emission and dispersal of dust in the atmosphere, and therefore do not always coincide with the location of dust sources [8]. Accurate knowledge of 
location of dust sources is also required to improve land management in the regions where dust sources are activated by human activities such as the abandonment of agricultural fields during droughts, overgrazing, and fires resulting from biomass burning [9]. It is, therefore, important to gain accurate knowledge of dust sources, their location, emission frequency, and how they respond to climate variability [10].

In order to locate sources of dust with high accuracy, observations should coincide with, or be closest in time to, the moment of emission [11]. High temporal resolution data provided by the European Organization for the Exploitation of Meteorological Satellites (EUMETSAT) Spinning Enhanced Visible and Infrared Imager (SEVIRI) instrument, carried on the Meteosat Second Generation (MSG) satellites, provides data at 15-min time intervals, at a spatial resolution of 3-5 km [12], allowing a precise record of dust emission sources and timings to be compiled. While the use of imagery at 15-minure resolution is expected to provide the highest accuracy, such analysis is very time consuming if conducted manually. The use of automated algorithms results in lower accuracy [1], but such algorithms are appropriate for analyzing activity of large-scale sources of dust (e.g., the Bodele depression). Manual mapping of dust sources is more appropriate to generate detailed databases (e.g., see References $[4,11,13]$ ) especially where smaller-scale dust sources are present (e.g., in the Middle East). Data storage requirements are also very high, as the use of 15 -min data generates approximately 35,000 images per year. It is important, therefore, to evaluate the benefits of using such high temporal resolutions on database quality, in order to maximize workflow efficiency.

The aim of this paper is to compare the accuracy of mapping dust sources using imagery at three different temporal resolutions (one image every 15-min, every 30-min, and every 60-min). Using EUMETSAT's 'Dust red/green/blue (RGB)' product, derived from SEVIRI data, discrete dust sources were observed across the entire Middle East region $\left(38.50^{\circ} \mathrm{N} ; 30.00^{\circ} \mathrm{E}-10.00^{\circ} \mathrm{N} ; 65.50^{\circ} \mathrm{E}\right.$; Figure 1$)$ at each temporal resolution. Analysis of the results will improve understanding of data requirements for future research, as well as providing new insights into dust climatology in the Middle East. The results of this analysis will be useful for aeolian scientists developing algorithms for automated dust-storm detection [1], as well as those using manual methods [4,11], enabling them to select an appropriate sampling interval for optimum detection, or to evaluate uncertainties when using lower sampling intervals. 


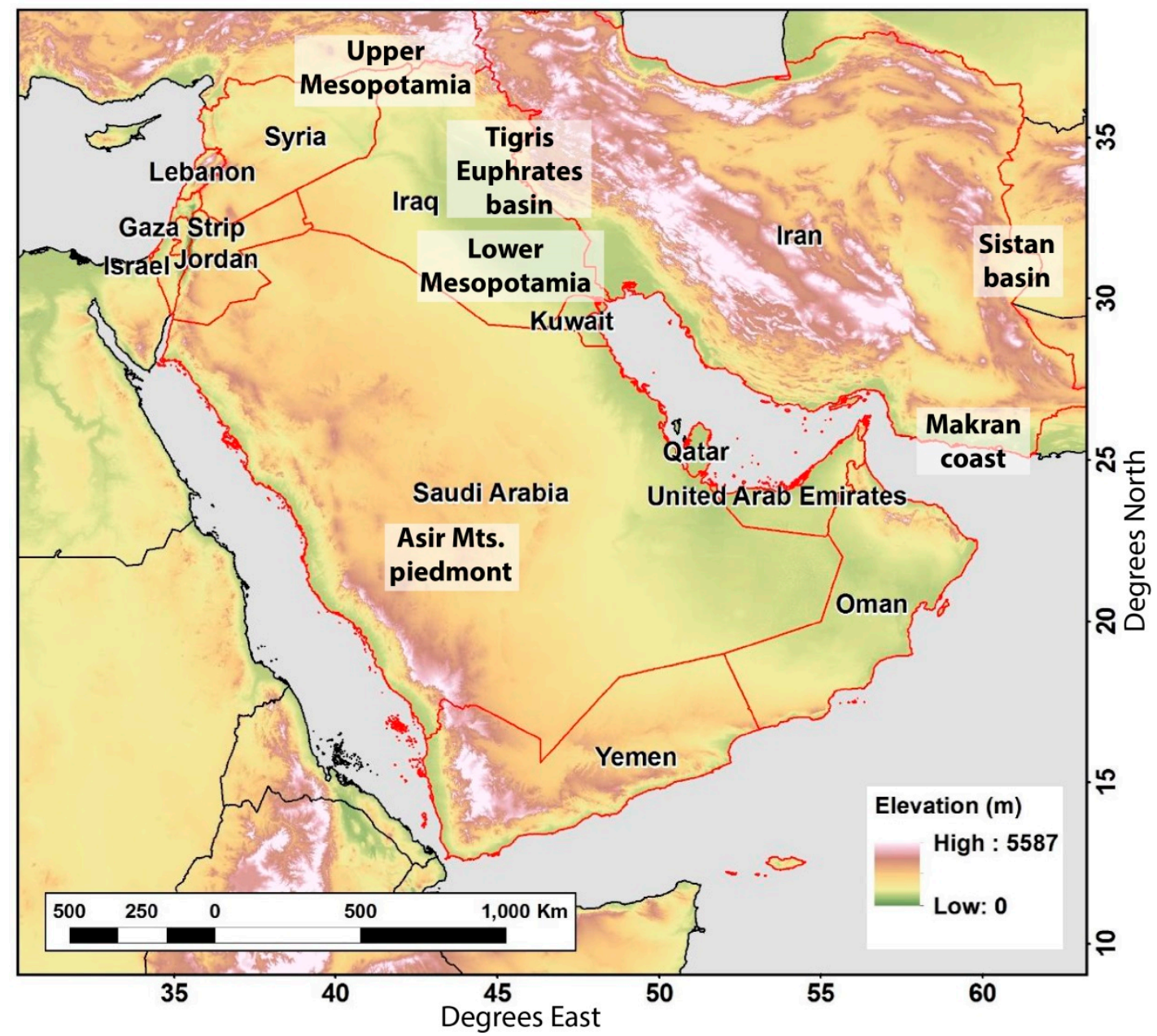

Figure 1. Study area of the Middle East. Red line depicts area of interest and national borders. Background Digital Elevation Model (DEM) provided by United States Geological Survey (USGS) has a $3 \mathrm{~km}$ spatial resolution and is represented as meters above mean sea level. Places mentioned in text shown in white boxes.

\section{Materials and Methods}

The SEVIRI sensor is based on EUMETSAT's Meteosat Second Generation (MSG) satellite, located $5^{\circ}$ West at the Equator, in a geostationary orbit. From this position, it provides $24-\mathrm{h}$ coverage of the Middle East, which lies towards the eastern limb of the Earth disk, at a spatial resolution of $4-5 \mathrm{~km}$ and 15-min maximum temporal resolution [12]. Dust emissions are identified using the SEVIRI 'Dust RGB' product [14]. Atmospheric dust is known to create a cooling anomaly in 'clear-sky' conditions in the thermal infrared part of the electromagnetic spectrum $(8.7$ to $12.0 \mu \mathrm{m})$ [7,15]. Relative RGB beam strengths are rendered from inter-channel brightness temperature differences (BTD), configured with specific thresholds (Table 1) to differentiate atmospheric dust from other 'thermally insulating' atmospheric components (e.g., clouds and soot from biomass burning) [16]. In the 'Dust RGB' product, dust appears as pink or magenta, meteorological clouds appear as brown or red, and bare surfaces appear as blue or white (Figure 2).

Dust emission source areas in the Middle East are located by subjective analysis of time series of these SEVIRI 'Dust RGB' images $[4,11,13]$. Here, lofted dust emission 'plumes' are manually identified by the First Author (Mark Hennen), and back-tracked through consecutive images to the point where the dust signal first appears in the scene. This is assumed to represent the dust source location, and each such dust emission event is recorded as a point source location and attributed with the time and date of the SEVIRI image where it first appears. 
We obtained the full 15-min SEVIRI 'Dust RGB' dataset for the calendar year 2006 and from this we sub-sampled images at 30-min and 60-min intervals. Three datasets of the observed dust emission point sources were derived from mapping of dust emission events at 15-min, 30-min, and 60-min temporal resolutions. The same operator (Mark Hennen) produced all three datasets. To avoid bias created by increasing observer skill over time, the operator trained on 6 months of data (January-June 2016, 60-min resolution) prior to the compilation of any of the three data sets-these training data are not included in the results; the full 60-min dataset was recreated once the training was completed.

Table 1. Spinning Enhanced Visible and Infrared Imager (SEVIRI) ‘Dust red/green/blue (RGB)’ product channel combinations and associated beam thresholds. BTD—brightness temperature differences.

\begin{tabular}{cccc}
\hline Beam & Channel & Measurement & Range \\
\hline Red & $12.0 \mu \mathrm{m}($ Ch. 10)-10.8 $\mathrm{m}(\mathrm{Ch} .9)$ & BTD $(\mathrm{K})$ & (Range -4 to 2 K) \\
\hline Green & $10.8 \mu \mathrm{m}($ Ch. 9)-8.7 $\mu \mathrm{m}(\mathrm{Ch} .7)$ & BTD (K) & (Range 0 to 15 K) \\
\hline Blue & $10.8 \mu \mathrm{m}($ Ch. 9) & BT (K) & (Range 261 to 289 K) \\
\hline
\end{tabular}

We assign a degree of confidence (DOC) score to each dust event (Figure 2) to indicate conditions where the visual identification of the dust signal becomes difficult, such as in the presence of meteorological clouds and high atmospheric water vapor content [16]. This enables us to examine seasonal variations in our ability to detect dust sources from the different temporal resolution datasets, which arise from meteorological conditions. The uncertainty is evaluated on a scale from 1 to 3 (where 'Level 1' indicates the highest confidence and 'Level 3' the lowest) and is recorded alongside each dust event.

Level 1 dust events occur where there is zero cloud cover (Figure 2; three clearly visible sources). A reduction in thermal contrast, created by regular night-time atmospheric temperature inversion and reduced skin temperature, precludes night-time dust events from Level 1 DOC in all cloud conditions. In the day, the surface is significantly warmer than the dust emission. At night, the reduction in surface temperature means any dust plume is at a more similar temperature to the surface, reducing the contrast used to identify the dust emission. The temperature inversion further reduces the contrast, inhibiting the cooling of the elevated dust emission. Similarly, increased ambiguity caused by extended atmospheric path length towards the edge of the Earth disk (as seen from the MSG satellite location at $3.5^{\circ} \mathrm{W}$ ) excludes all dust events in the eastern reaches of Iran (greater than $60^{\circ} \mathrm{E}$ ) from Level $1 \mathrm{DOC}$.

Level 2 dust events occur where there is partial cloud cover in the proximity of a dust emission source. These events are defined by the presence of meteorological clouds downwind of an emission source, with clear-sky conditions upwind; with the deflating surface visible during the hour prior to, and after, the dust emission event. In contrast to Level 1 events, such conditions are likely to be influenced by the Thermal Infrared (TIR) absorptive characteristics of atmospheric column water vapor (CWV) [17], associated with moist convective systems [18]. In these conditions, increased humidity suppresses the dust signal in the RGB rendering, most significantly reducing the red beam $(\Delta \mathrm{TB} / 12.0-10.8 \mu \mathrm{m})$ in all (dusty or clear-sky) conditions making it more challenging to precisely detect discrete sources. Equally, coastal dust emissions, emanating from onshore winds (indicated by the trajectory of the dust plume) are attributed Level 2 DOC due to the probable increase in CWV relative to continental air masses. 


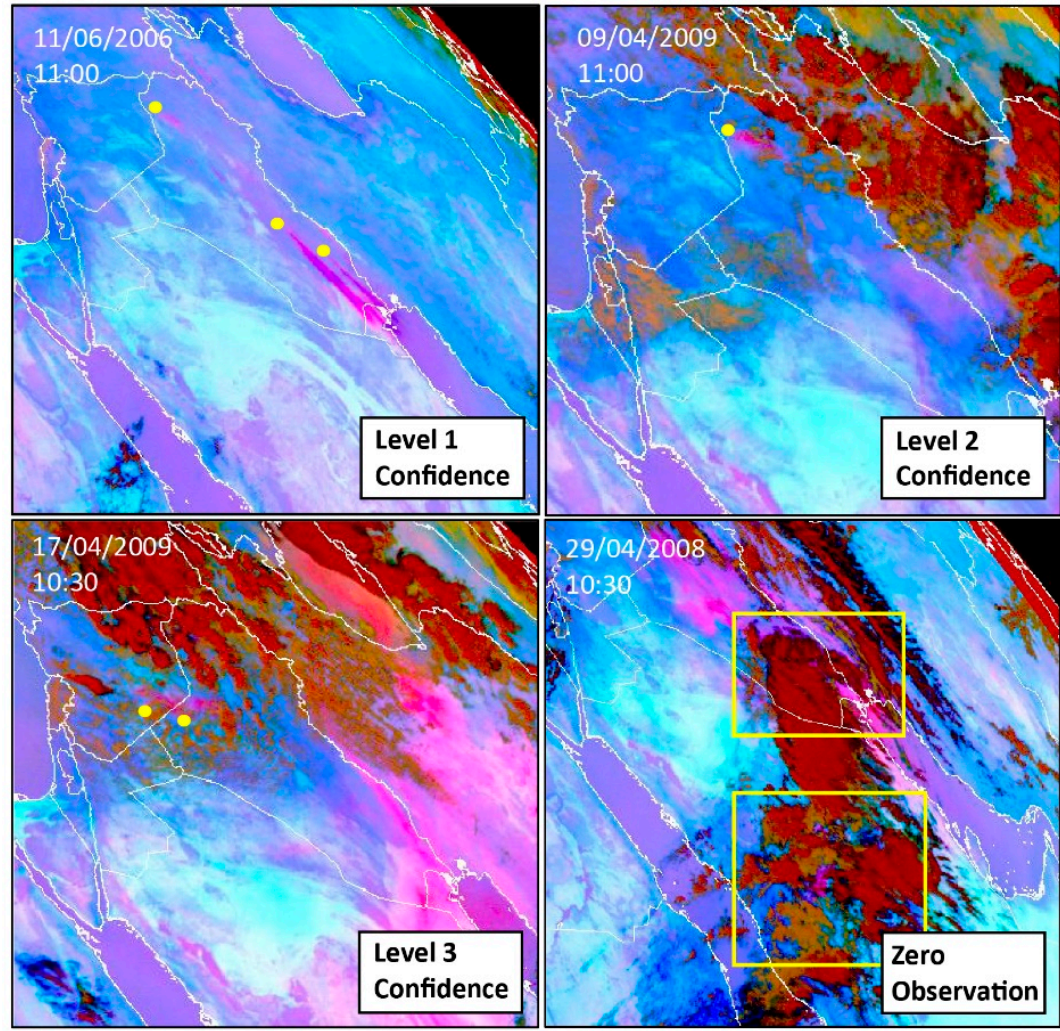

Figure 2. Examples of SEVIRI dust RGB imagery where dust emission surfaces (yellow dots) are observed at different degrees of confidence (DOC).

Level 3 dust events equate to dust emissions which occur within or under thin banks of cloud where an emission surface is visible at the moment of dust emission. These types of events will typically have banks of meteorological clouds upwind and downwind of the emission source. The detection of these emissions is only possible through a careful inspection of dust emission evolution by backward and forward tracking of the plume in sequential images.

Despite their limitations for source point location, both Level 2 and Level 3 DOC data remain useful as indicators of dust source activity. In addition, we use them here to investigate how DOC changes seasonally, as this can have important implications for establishing an accurate dust climatology dataset.

Some of the observed dust plumes failed to meet the criterion of Level 3 confidence and were omitted from the dust source inventory as it was not possible to establish accurate location of these dust sources. Such events included (i) dust emerging under a large convective system or active front, and (ii) blowing dust that travels into the study area from an outside source (i.e., North Africa).

\section{Results}

Figure 3 shows annual cycles of dust emission frequencies derived using data with different temporal resolutions. A reduction in the monthly frequencies of dust events with a decrease in temporal resolution of the acquired imagery was evident, particularly between May and August. A decrease in temporal resolution from 15-min to 60-min resulted in a reduction of the total number of events of $50 \%$ over the year. The use of 30 -min observations resulted in recording $17 \%$ fewer events than using the 15-min data.

Differences in observations vary considerably by season, with June-July-August (JJA) showing both a peak in the dust-storm activity in the Middle East overall (as opposed to individual regions) and the greatest divergence between the three datasets. Compared to the 15-min data, the frequency of the JJA recorded dust events reduced by $34 \%$ at the 30 -min time steps and $64 \%$ at the 60 -min time steps. The monthly peak in dust events was recorded in July in all three datasets, with frequencies of 
492, 316, and 195 events, using data obtained at 15-min, 30-min, and 60-min intervals, respectively. The 60-min dataset consistently produced fewer dust events in each month; the 15-min and 30-min data sets were relatively consistent throughout the rest of the year, but for months outside the peak summer period of dust storms, the 30-min dataset can yield marginally more dust events than the 15-min dust events due to increased meteorological cloud coverage during these months, an issue we discuss in Section 4.2 below.

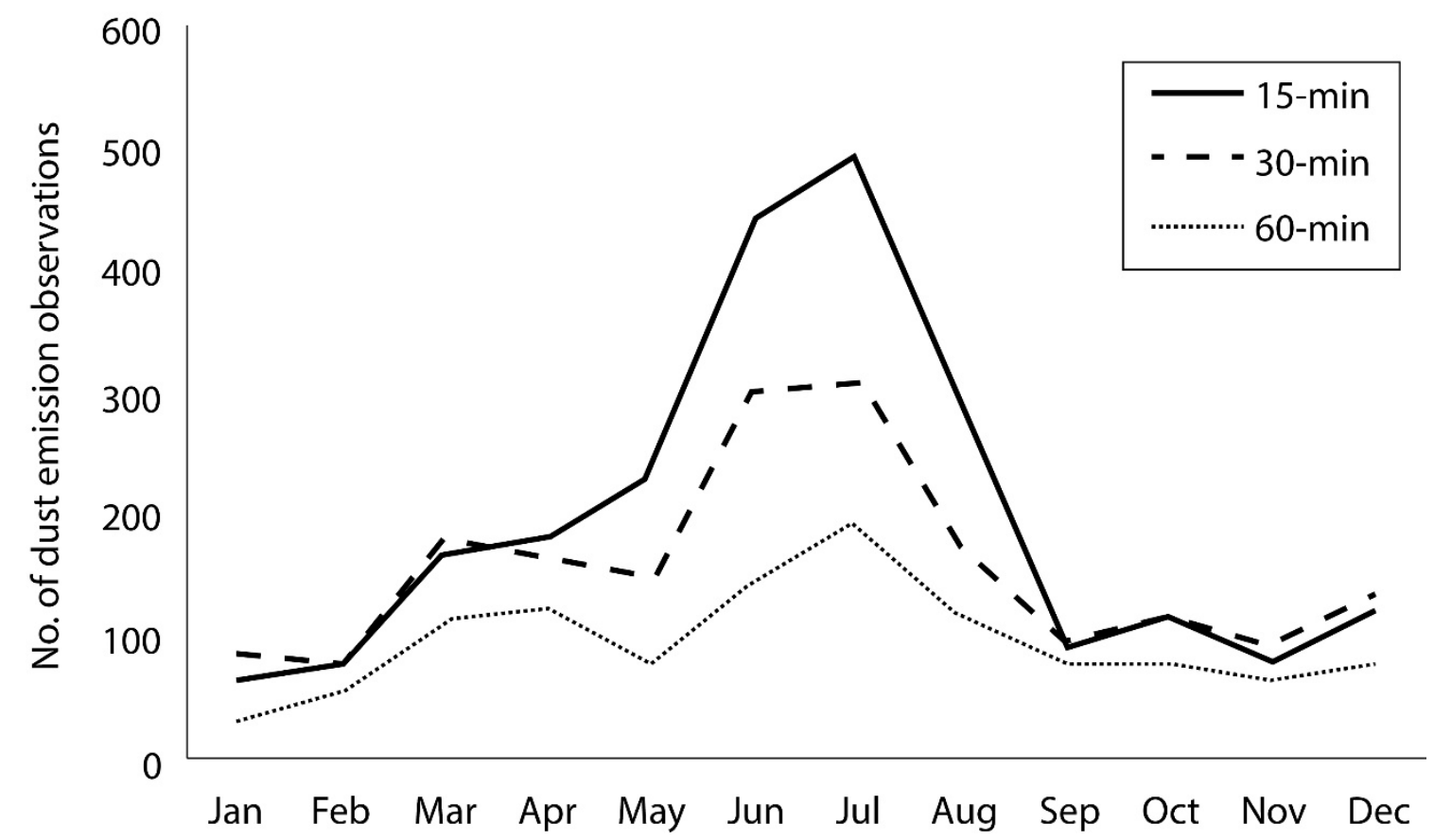

Figure 3. Comparison of 2006 dust emission events (per month) in the Middle East recorded using SEVIRI ‘Dust RGB' data with 15-min, 30-min, and 60-min temporal resolution.

Analysis of the spatial distributions of the datasets identified a distinctive change in pattern, particularly in data retrieved at 60-min time steps (Figure 4). Figure 4 describes the differences in the number of observations observed in each $0.5^{\circ}$ grid cell when compared to the 15 -min dataset. To highlight only areas of significant change in each cell, Figure 4 includes only cells where the difference in the number of observed events is greater than five when compared to the 15-min dataset. The comparison highlights a greater consensus between the 15-min and 30-min datasets (Figure 4, bottom left panel), producing fewer grid cells of significant difference than the 15-min and 60-min comparison (Figure 4, bottom right panel). Compared to the 15-min dataset, both the 30-min and 60-min datasets show the greatest difference in areas of highest emission frequency (Figure 4 , bottom panels), such as Upper Mesopotamia in Iraq and Syria $\left(35^{\circ}-36^{\circ} \mathrm{N} ; 40^{\circ}-42^{\circ} \mathrm{E}\right)$ and the Sistan Basin, Iran $\left(30^{\circ}-31.5^{\circ} \mathrm{N} ; 61^{\circ}-62^{\circ} \mathrm{E}\right)$; see Figure 1 for locations. This is because, in the main dust-producing areas, the higher temporal resolution data are able to pick out more detail, and therefore distinguish more individual events. There are some exceptions evident, notably in the 15- and 30-min comparison in Saudi Arabia. Here, the dust emission events, while frequent, were relatively small, and several were missed in the 15-min analysis, highlighting a limitation of the manual detection method. Furthermore, the 60-min datasets fails to identify dust emissions along the coastline (Figure 4, bottom right panel), omitting a significant number of observations along the Makran Coastline, Iran $\left(25^{\circ}-26^{\circ} \mathrm{N} ; 57^{\circ}-61^{\circ} \mathrm{E}\right)$. However, these events are detected equally well in the 30-min and 15-min data, although the DOC levels are lower here as a result of meteorological cloud cover. 


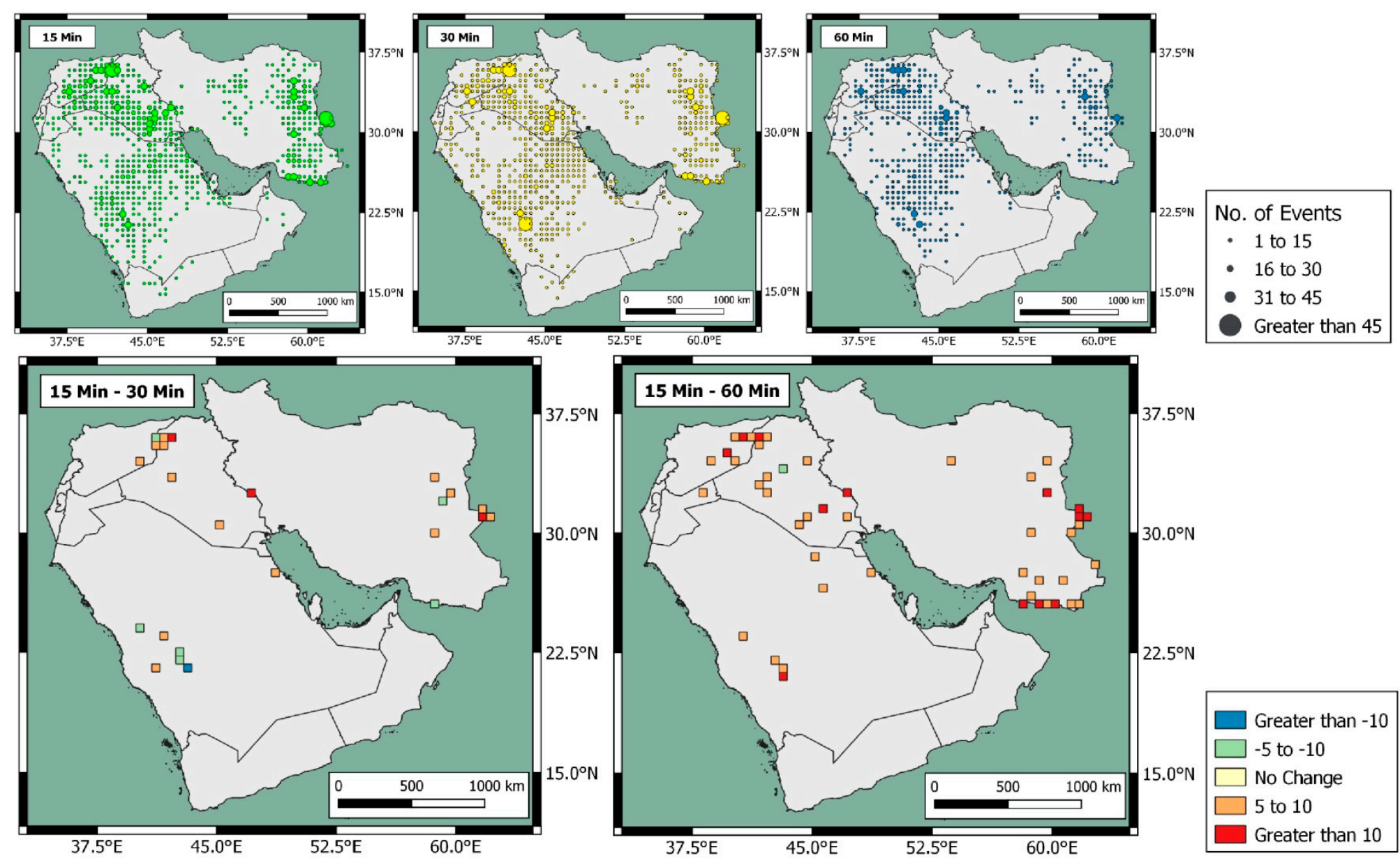

Figure 4. Top: Spatial distribution of observed SEVIRI dust emission sources at 15-min (green), 30-min (yellow), and 60-min (blue) temporal resolutions. Observations are binned into $0.5^{\circ} \times 0.5^{\circ}$ grid; circle size represents count of observations made within the grid cell it is centered over. Bottom: Dust emission observations taken at 15-min resolution compared to 30-min and 60-min temporal resolution on a $0.5^{\circ} \times 0.5^{\circ}$ grid. No change is recorded if the number of observations is within five of the 15-min dataset. 


\section{Discussion}

These differences in the numbers of dust emission events recorded using three datasets with different temporal resolutions can be attributed to two factors. These are (i) spatio-temporal clustering and (ii) seasonal cloud conditions.

\subsection{Spatio-Temporal Clustering}

A large proportion of the recorded dust emission events are concentrated in relatively small regions, represented by a few $0.5^{\circ}$ grid cells in all three datasets (Figure 4). In 849 grid cells, a minimum of one dust event is registered in each dataset. These account for $41 \%$ (2.1 million $\left.\mathrm{km}^{2}\right)$ of the Middle East land area. Most dust emissions originate from discrete zones of frequent emission (Figure 4). These emission 'hot spots' account for only $6 \%\left(0.28\right.$ million $\left.\mathrm{km}^{2}\right)$ of the total land surface, yet produce $51 \%$ of all dust emission events. In all three datasets, these hot spots are located in four main areas. These include: (i) upper Mesopotamia, on the border of Iraq and Syria $\left(35^{\circ}-36^{\circ} \mathrm{N} ; 40^{\circ}-42^{\circ} \mathrm{E}\right)$; (ii) lower Mesopotamia, at the confluence of the Tigris and Euphrates rivers $\left(30^{\circ}-32^{\circ} \mathrm{N} ; 43^{\circ}-46^{\circ} \mathrm{E}\right)$; (iii) the piedmont regions of the Asir Mountains in central Saudi Arabia $\left(20^{\circ}-22^{\circ} \mathrm{N} ; 42^{\circ}-43.5^{\circ} \mathrm{E}\right)$; and (iv) the Sistan Basin in eastern Iran $\left(30^{\circ}-31.5^{\circ} \mathrm{N} ; 61^{\circ}-62^{\circ} \mathrm{E}\right)$. See Figure 1 for locations. Typically, these areas generate large dust clouds, developing through emissions from multiple discrete point dust sources [19]. This clustering of source areas is typical of dryland dust emitting landscapes, caused by preferential accumulation of fine sediments associated with specific landforms, which are readily deflated [20]. Typically, these are characterized by small fluvial and lacustrine features (e.g., flood plains, ephemeral channels, and seasonal lakes), where regular, fresh inputs of alluvium are subsequently winnowed by aeolian activity [21]. The probability of downwind sources being obscured by upwind-derived dust plumes is increased in these regions, where multiple dust sources regularly emit in close proximity (such as the Tigris-Euphrates Basin-Figure 4).

Figure 5 and Table 2 illustrate how the near-simultaneous activation of discrete dust sources, within a small dust source area, can create inconsistencies in the number of recognized dust emission events when observed at the different temporal resolutions. Each Tn represents a 15-min time step (the highest temporal resolution available), within a 60-min observation window. At 60-min resolution, only T1 and T5 would be observable; 30-min resolution observes T1, T3, and T5; 15-min resolution observes all images.

Surface deflation (distinguished by the red dots) most upwind of the emission cone (brown triangle) will commence as the north-westerly winds exceed a surface cohesion threshold of wind speed. In this example, all sources are assumed to have the same wind speed threshold. At T1, wind speed does not exceed the surface threshold in the region, resulting in no dust emission and zero dust events are observed in all three datasets. As threshold-exceeding wind speeds propagate south east across the area, the resulting dust plume will increasingly obscure the surface downwind of the initial emission site. Importantly, as this example shows, 60-min frequency data will struggle to detect all discrete sources in these conditions, with the first and only observation made at T5. With the sources S2 and S3 obscured, 60-min resolution only records one point source 'event' across the area and period of observation. 


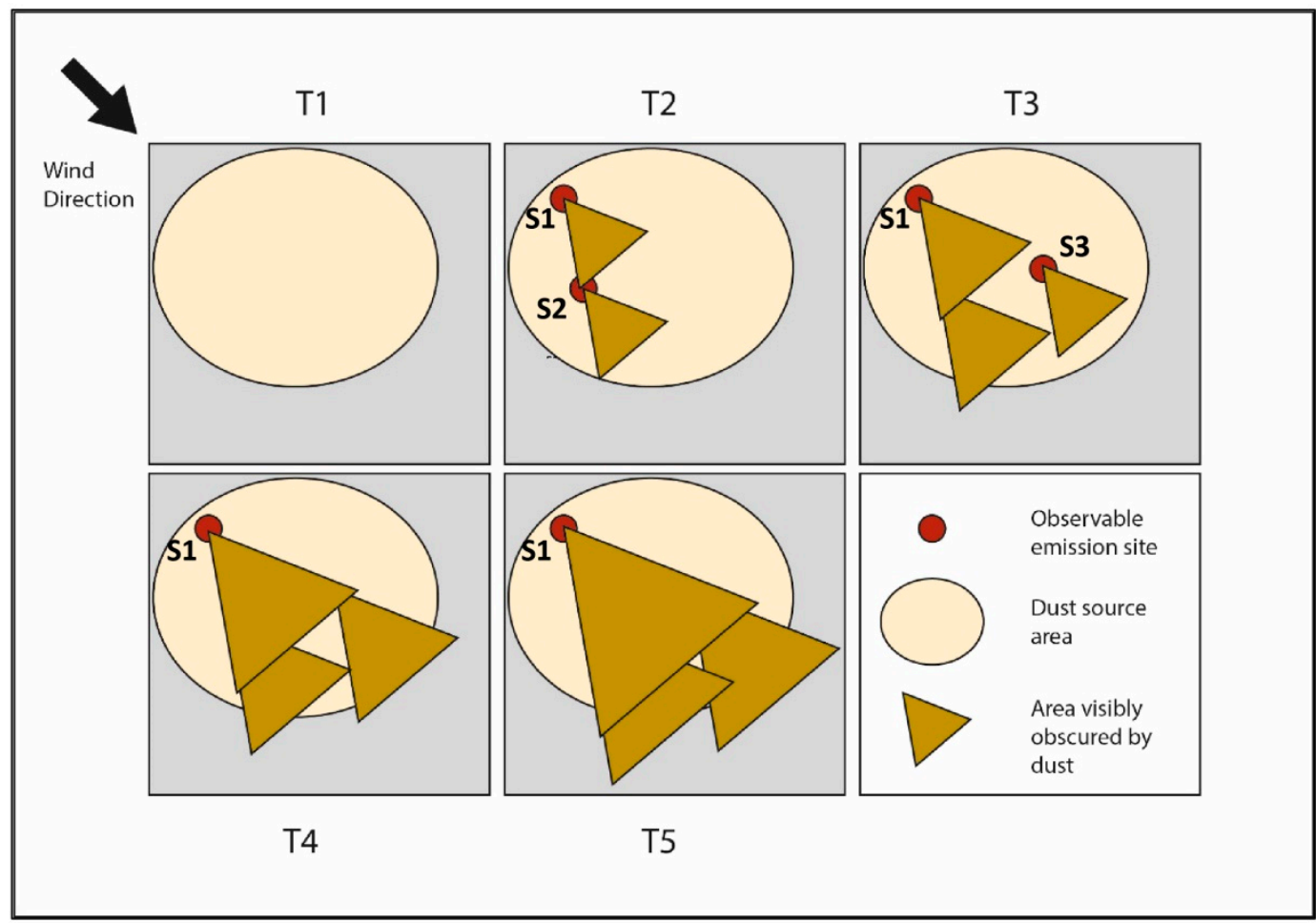

Figure 5. Schematic illustrating the formation of dust point sources (S1, S2, and S3-red dots) within a dust source area at 15-min time steps. T1 to T5 are observable only in 15-min resolution data; T1, $\mathrm{T} 3$, and $\mathrm{T} 5$ are observable at 30 -min resolution; T1 and T5 are observable at 60 -min resolution. Dust sources depicted by red dots are only visible when not obscured by dust emissions upwind (expressed by brown triangles).

Table 2. The number of dust point sources identified at $15-\mathrm{min}, 30-\mathrm{min}$, and 60-min resolutions from Figure 5.

\begin{tabular}{cccc}
\hline & \multicolumn{3}{c}{ Number of Dust Emission Events Observed } \\
\hline Temporal Resolution & 15-min & 30-min & 60-min \\
\hline T1 & 0 & 0 & 0 \\
\hline T2 & 2 & No image available & No image available \\
\hline T3 & 1 & 2 & No image available \\
\hline T4 & 0 & No image available & No Image available \\
\hline T5 & 0 & 0 & 1 \\
\hline Total & 3 & 2 & 1 \\
\hline
\end{tabular}

This downwind obscurement is especially effective when emissions from multiple surfaces are initiated near-simultaneously. In the Middle East, the simultaneous activation of multiple sources occurs following the formation of nocturnal low-level jets (LLJs), fast moving currents of air forming at the top of the boundary layer, over the Sistan Basin, eastern Iran [22,23] and the Tigris-Euphrates Basin [24]. LLJs develop when intensive nocturnal temperature inversions, frequently generated over desert surfaces during summer months, result in the decoupling of the air above and below the inversion (approximately $500 \mathrm{~m}$ above ground level) [4]. Free from surface frictional forces, LLJs accelerate, peaking in the early morning [18]. Mid-late morning convection degrades the temperature inversion, transferring the LLJ momentum back towards the surface, creating high wind speeds near the surface and resulting in dust emissions at a specific time of day, typically in the late morning [25]. In this study, $62 \%$ of the dust events were recorded between 06:00 and 12:00 (local time) in all three data 
sets (Figure 6). This temporal clustering of dust emission prevents the observer from distinguishing all downwind discrete sources using lower frequency observations, as they are obscured by upwind dust emissions as outlined above. This explains some of the differences between the three datasets, especially during peak dust activity (JJA—see Figure 3), when the larger number of events exacerbates the spatio-temporal clustering and resulting downwind obscurement.

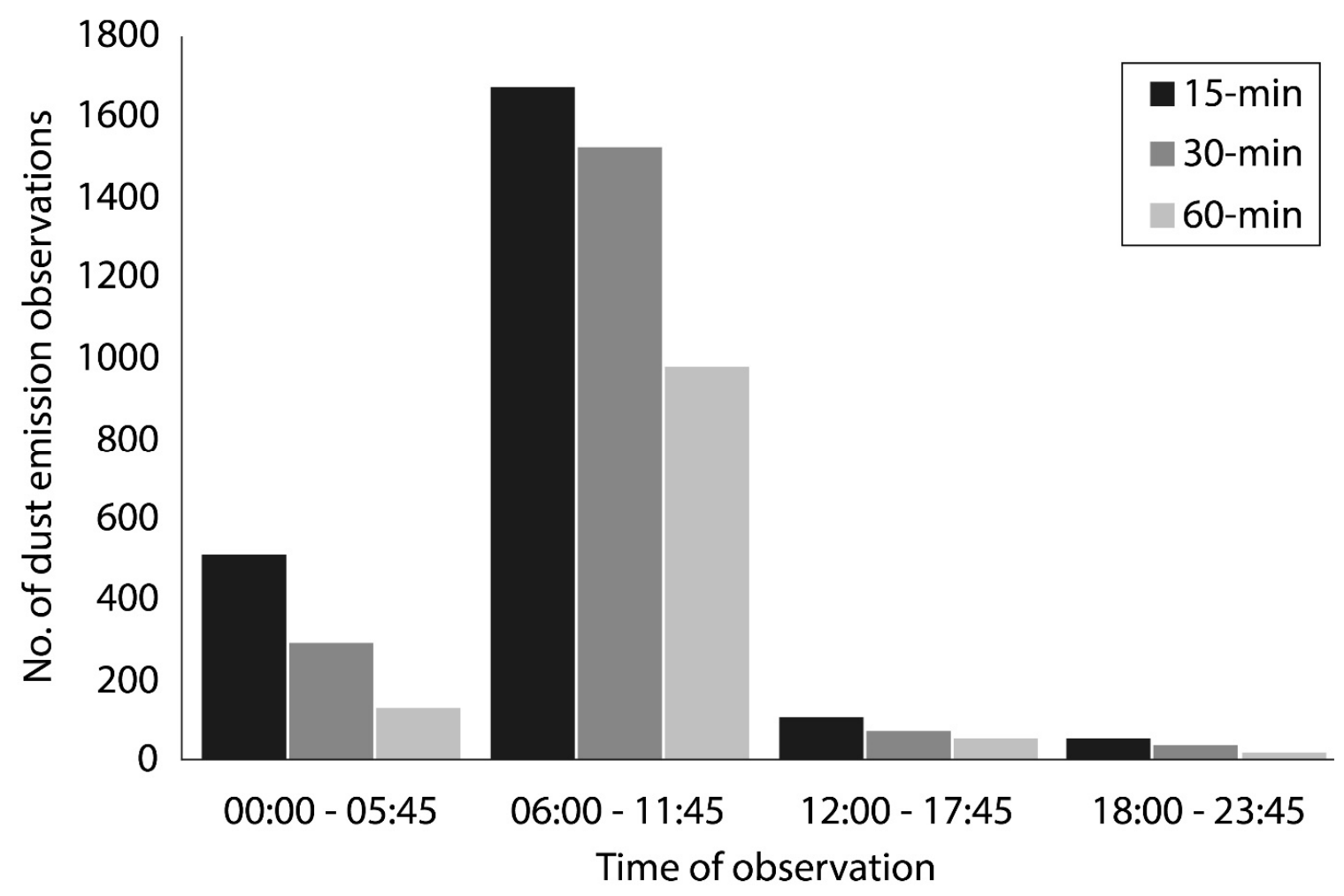

Figure 6. Diurnal plot of all 2006 dust emission observations binned into four $(6 \mathrm{~h})$ time segments at each 15-min, 30-min, and hourly temporal resolution.

As Figure 4 shows, dust sources in the Tigris-Euphrates Basin are clustered along a NW to SE corridor. Here, the persistent north-westerly Shamal (Arabic for northerly) winds during JJA transport $94 \%$ of all dust emissions towards the south-east. With many discrete sources in close proximity along this alignment, these conditions preclude the lower temporal resolution data from detecting discrete sources in downwind areas, increasing the variation in frequency of detected emissions between the three datasets. During the other seasons, the emission frequencies recorded in the three datasets are closer (Figure 3). This is a result of the overall reduction in dust storms across the entire region and the relative increase in dust emissions from sources outside the Tigris-Euphrates Basin, specifically the rest of the Arabian Peninsula. Here, the numbers of non-JJA dust emissions are comparable to those recorded in the Tigris-Euphrates Basin during the same period, but sources are distributed over a wider area, resulting in less obscurement due to the clustering effect.

\subsection{Seasonal Cloud Conditions}

The similarity of the results outside the summer months can also be attributed to increased cloud cover. Dust emissions associated with increased cloud cover, such as those generated by an active weather front, present challenges for remote sensing analysis. Firstly, when directly above the emission source, meteorological cloud obscures dust on the image, causing events to be missed. Secondly, the associated increase in CWV can mask the dust signal in the RGB rendering [16]. In contrast to the predominantly clear-sky conditions associated with the summer Shamal winds [26], high wind speeds during non-JJA months are frequently created by depressions travelling from the eastern 
Mediterranean and North Africa [27]. Such systems result in increased cloud cover, thunderstorms, and high wind speeds as they progress eastward along their transport corridor [28], generating dust events that cannot be observed by SEVIRI data [27].

The Makran coast region (south-east coast of Iran) shows significant differences between the 15-min and 60-min datasets (Figure 4). This area is particularly problematic for dust observation due to frequent cloud formation and high CWV content [29]. Near-shore convective cloud patterns obscure atmospheric dust soon after emission and the 60-min dataset is unable to recognize many dust emission events with an acceptable level of confidence. Here, the use of 15-min observations enables a significant increase in dust event identification (compare the 15- and 60-min animations in Supplementary Materials, Figures S1 and S2).

The increased influence of cloudy conditions during non-JJA dust emissions is demonstrated by the increased percentage of DOC scores 2 or 3 (Figure 7). Meteorological clouds form and move independently from dust emissions below, reducing the ability of the observer to distinguish smaller downwind sources at any image frequency. The result is a bias towards the most readily recognizable emission point source, typically found most upwind (S1 in Figure 5), causing the differences between numbers of dust emission events recorded in the 15-, 30-, and 60-min datasets to decrease.

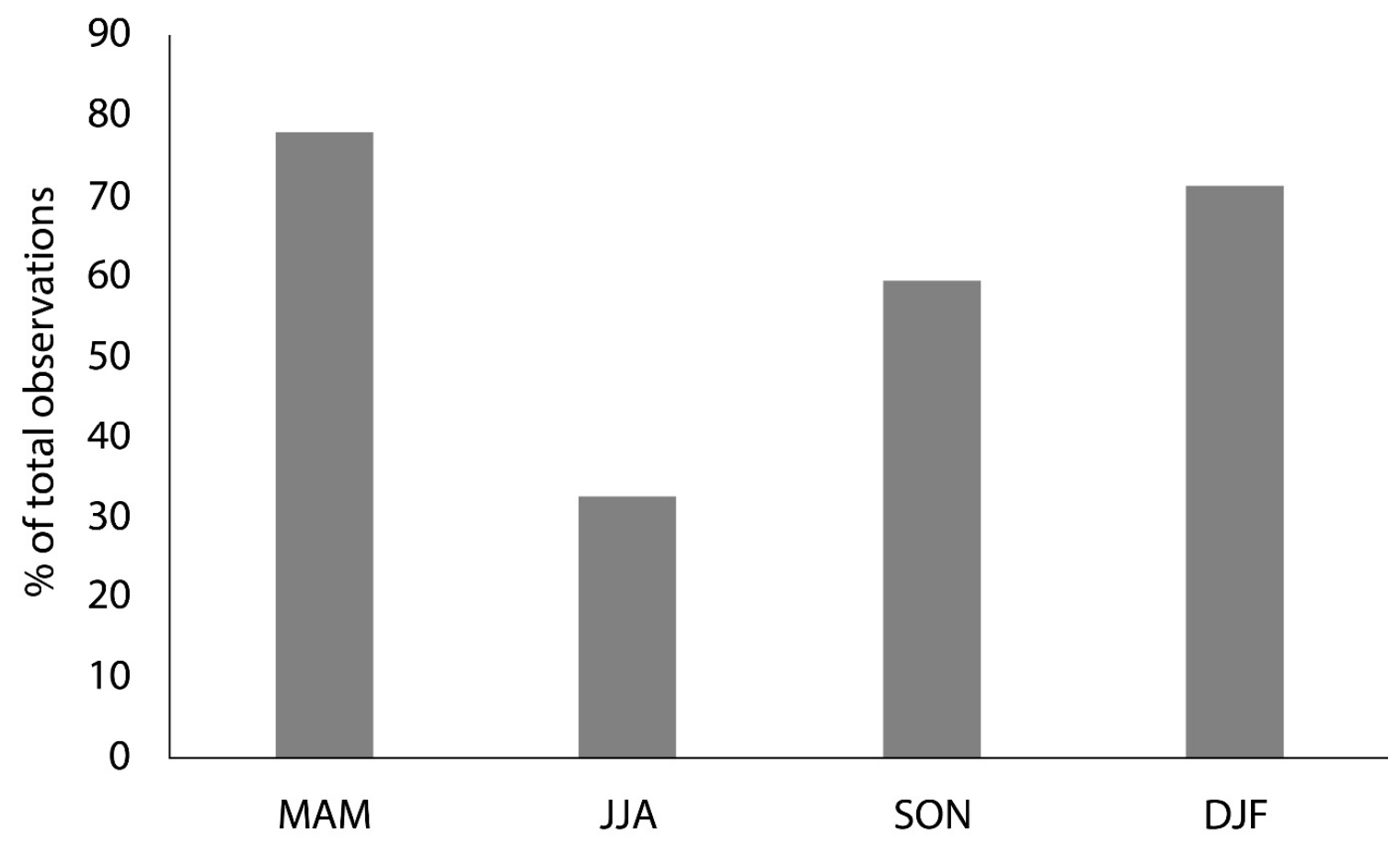

Figure 7. Percentage of dust events in the study area with degree of confidence level 2 or 3 in all three datasets, demonstrating the variation between seasons.

It is important to remember that the three datasets are compiled based on the subjective interpretation of the operator, thus the results are unlikely to be exactly reproduced by another operator. When digitizing the aerial extent of dust clouds in SEVIRI 'Dust RGB' data, Ashpole and Washington [30] compared the results of two experienced independent viewers, finding a 77\% agreement during daylight hours and only $52 \%$ at night. Importantly, the low agreement in their study is due to the use of single snapshot analysis, with only one image digitized of North Africa for each day (12:00 UTC) and night (03:00 UTC) of observation. By using sequential images in this investigation, it is expected that the differences between the three datasets provide a reliable indicator of the increased accuracy derived from sub-hourly image analysis. However, we cannot discount the possibility that a proportion of the observed differences may relate to the subjective method used. 


\section{Conclusions}

This paper has examined the effect of different temporal resolutions of SEVIRI 'Dust RGB' observations on the number and spatial distribution of observed dust emission events in the Middle East. The results show a reduction in the number of events recorded when using less frequent observations, reducing by $17 \%$ for 30 -min resolution and $50 \%$ for $60-\mathrm{min}$ resolution, compared to the $15-\mathrm{min}$ data. These differences change seasonally, with the biggest difference observed in the summer months (34\% for $30-\mathrm{min}$ and $64 \%$ for 60 -min resolution). The significant increase in the number of events detected in the 15-min dataset is explained by the clustering of events in the summer months, and this is heavily influenced by the numerous, small events in the Mesopotamia region. The 15-min data enable much better identification of individual events here, compared to less frequent observations, as explained by Figure 5. Outside of the summer months, uncertainty caused by meteorological cloud reduces the difference in results between the datasets. Under these conditions, there is no significant difference between the 15- and 30-min datasets in the Makran Coast region, but the 60-min dataset records no events here. Thus, numbers of emission events recorded in the 15-min and 30-min datasets converge during autumn months (September, October, November - SON) and winter months (December, January, February - DJF). The 15-min and 30-min data are in relatively close agreement through the spring months (March, April, May - MAM), although the 60-min data records a significant decrease ( $45 \%$ reduction compared to the 15 -min dataset) due to the increased influence of cloudy conditions, as discussed in Section 4.2.

The 60-min dataset also fails to identify dust sources in certain geographical areas. Again, this is most evident along the Makran coast, where near-shore convective cloud patterns obscure atmospheric dust soon after emission. Here, only the 15- and 30-min datasets permit the identification of dust emission events to the required degree of confidence.

These results indicate that, over much of the Middle East, 30-min data are adequate to map most dust sources under good conditions, that is, when they are clear of upwind dust plumes or meteorological cloud. However, the 15-min data provide a much more detailed record in areas such as in Mesopotamia. This is because the Tigris-Euphrates Basin is characterized by many small dust sources which tend to be spatially clustered, meaning that downwind sources are readily obscured by upwind sources during major deflation events. Observations at $30 \mathrm{~min}$ and $60 \mathrm{~min}$ are also of limited use where the emission is instigated by diurnal atmospheric processes such as the breakdown of nocturnal LLJs, where the daily total emissions are limited to a few hours of the day (between 06:00 and 12:00, local time).

Supplementary Materials: The following are available online at http://www.mdpi.com/2072-4292/11/8/918/s1, Figure S1: Animated GIF of 15-min SEVIRI ‘Dust RGB' images covering the period 05:00-22:00 UTC on 13/05/2006. Atmospheric dust appears in pink and magenta colours, demonstrating how meteorological clouds (dark red colours) interfere with the ability to trace dust events to emission sources along the Makran coast of Iran. Figure S2: Animated GIF of 60-min SEVIRI ‘Dust RGB' images covering the same period as Figure S1 (05:00-22:00 UTC on 13/05/2006). Note the combined impact of presence of meteorological cloud and reduced temporal resolution on ability to trace dust events to emission sources along the Makran coast of Iran.

Author Contributions: M.H. formulated the research design and methodology, processed and analyzed the data and wrote the draft manuscript. K.W. and M.S. revised the manuscript and supervised. All authors contributed and approved the final manuscript before submission.

Funding: This research was funded by a University of Reading PhD studentship awarded to M.H.

Acknowledgments: The authors would like to thank Helen Brindley and Jonathan Murray (Department of Physics, Imperial College London), for their help and advice in accessing the SEVIRI 'Dust RGB' data used in this project.

Conflicts of Interest: The authors declare no conflict of interest. The funders had no role in the design of the study; in the collection, analyses, or interpretation of data; in the writing of the manuscript, and in the decision to publish the results. 


\section{References}

1. Ashpole, I.; Washington, R. A new high-resolution central and western Saharan summertime dust source map from automated satellite dust plume tracking. J. Geophys. Res. Atmos. 2013, 118, 6981-6995. [CrossRef]

2. Choobari, O.A.; Zawar-Reza, P.; Sturman, A. The global distribution of mineral dust and its impacts on the climate system: A review. Atmos. Res. 2014, 138, 152-165. [CrossRef]

3. Vishkaee, F.A.; Flamant, C.; Cuesta, J.; Oolman, L.; Flamant, P.; Khalesifard, H.R. Dust transport over Iraq and northwest Iran associated with winter Shamal: A case study. J. Geophys. Res. Atmos. 2012, 117, D03201. [CrossRef]

4. Schepanski, K.; Tegen, I.; Todd, M.C.; Heinold, B.; Bönisch, G.; Laurent, B.; Macke, A. Meteorological processes forcing Saharan dust emission inferred from MSG-SEVIRI observations of subdaily dust source activation and numerical models. J. Geophys. Res. Atmos. 2009, 114, D10201. [CrossRef]

5. Prospero, J.M.; Ginoux, P.; Torres, O.; Nicholson, S.E.; Gill, T.E. Environmental characterization of global sources of atmospheric soil dust identified with the NIMBUS 7 Total Ozone Mapping Spectrometer (TOMS) absorbing aerosol product. Rev. Geophys. 2002, 40, 1002. [CrossRef]

6. Myhre, G.; Shindell, D.; Bréon, F.-M.; Collins, W.; Fuglestvedt, J.; Huang, J.; Koch, D.; Lamarque, J.-F.; Lee, D.; Mendoza, B.; et al. Anthropogenic and Natural Radiative Forcing. In Climate Change 2013: The Physical Science Basis. Contribution of Working Group I to the Fifth Assessment Report of the Intergovernmental Panel on Climate Change; Stocker, T.F., Qin, D., Plattner, G.-K., Tignor, M., Allen, S.K., Boschung, J., Nauels, A., Xia, Y., Bex, V., Midgley, P.M., Eds.; Cambridge University Press: Cambridge, UK, 2013; pp. 659-740.

7. Ackerman, S.A. Remote sensing aerosols using satellite infrared observations. J. Geophys. Res. Atmos. 1997, 102, 17069-17079. [CrossRef]

8. Kahn, R.A.; Nelson, D.L.; Garay, M.J.; Levy, R.C.; Bull, M.A.; Diner, D.J.; Martonchik, J.V.; Paradise, S.R.; Hansen, E.G.; Remer, L.A. MISR aerosol product attributes and statistical comparisons with MODIS. IEEE Trans. Geosci. Remote Sens. 2009, 47, 4095-4114. [CrossRef]

9. Middleton, N.J. Desert dust hazards: A global review. Aeolian Res. 2017, 24, 53-63. [CrossRef]

10. Ginoux, P.; Prospero, J.M.; Gill, T.E.; Hsu, N.C.; Zhao, M. Global-scale attribution of anthropogenic and natural dust sources and their emission rates based on MODIS Deep Blue aerosol products. Rev. Geophys. 2012, 50, RG3005. [CrossRef]

11. Schepanski, K.; Tegen, I.; Macke, A. Comparison of satellite based observations of Saharan dust source areas. Remote Sens. Environ. 2012, 123, 90-97. [CrossRef]

12. Banks, J.R.; Brindley, H.E. Evaluation of MSG-SEVIRI mineral dust retrieval products over North Africa and the Middle East. Remote Sens. Environ. 2013, 128, 58-73. [CrossRef]

13. Schepanski, K.; Tegen, I.; Laurent, B.; Heinold, B.; Macke, A. A new Saharan dust source activation frequency map derived from MSG-SEVIRI IR-channels. Geophys. Res. Lett. 2007, 34, L18803. [CrossRef]

14. Lensky, I.M.; Rosenfeld, D. Clouds-Aerosols-Precipitation Satellite Analysis Tool (CAPSAT). Atmos. Chem. Phys. Discuss. 2008, 8, 4765-4809. [CrossRef]

15. Volz, F.E. Infrared Optical Constants of Ammonium Sulfate, Sahara Dust, Volcanic Pumice, and Flyash. Appl. Opt. 1973, 12, 564. [CrossRef]

16. Brindley, H.; Knippertz, P.; Ryder, C.; Ashpole, I. A critical evaluation of the ability of the Spinning Enhanced Visible and Infrared Imager (SEVIRI) thermal infrared red-green-blue rendering to identify dust events: Theoretical analysis. J. Geophys. Res. Atmos. 2012, 117, D07201. [CrossRef]

17. Hsu, N.C.; Tsay, S.; King, M.D.; Herman, J.R. Aerosol Properties over Bright-Reflecting Source Regions. IEEE Trans. Geosci. Remote Sens. 2004, 42, 557-569. [CrossRef]

18. Knippertz, P.; Todd, M.C. The central west Saharan dust hot spot and its relation to African easterly waves and extratropical disturbances. J. Geophys. Res. Atmos. 2010, 115, D12117. [CrossRef]

19. Mahowald, N.M.; Bryant, R.G.; Del Corral, J.; Steinberger, L. Ephemeral lakes and desert dust sources. Geophys. Res. Lett. 2003, 30, 30-33. [CrossRef]

20. Wang, X.; Zhou, Z.; Dong, Z. Control of dust emissions by geomorphic conditions, wind environments and land use in northern China: An examination based on dust storm frequency from 1960 to 2003. Geomorphology 2006, 81, 292-308. [CrossRef]

21. Bullard, J.; Baddock, M.; McTainsh, G.; Leys, J. Sub-basin scale dust source geomorphology detected using MODIS. Geophys. Res. Lett. 2008, 35, L15404. [CrossRef] 
22. Barough, M.S.; Kashani, S.S.; Bidokhti, A.A.; Ranjbar, A. The Numerical Study of Low Level Jets Formation in South Eastern of Iran. World Acad. Sci. Eng. Technol. Int. J. Environ. Chem. Ecol. Geol. Geophys. Eng. 2010, 4, 488-493.

23. Choobari, O.A.; Zawar-Reza, P.; Sturman, A. Low level jet intensification by mineral dust aerosols. Ann. Geophys. 2013, 31, 625-632. [CrossRef]

24. Bou Karam, D.; Flamant, C.; Chaboureau, J.P.; Banks, J.; Cuesta, J.; Brindley, H.; Oolman, L. Dust emission and transport over Iraq associated with the summer Shamal winds. Aeolian Res. 2017, 24, 15-31. [CrossRef]

25. Rezazadeh, M.; Irannejad, P.; Shao, Y. Climatology of the Middle East dust events. Aeolian Res. 2013, 10, 103-109. [CrossRef]

26. Hamidi, M.; Kavianpour, M.R.; Shao, Y. A quantitative evaluation of the 3-8 July 2009 Shamal dust storm. Aeolian Res. 2017, 24, 133-143. [CrossRef]

27. Kutuzov, S.; Shahgedanova, M.; Mikhalenko, V.; Ginot, P.; Lavrentiev, I.; Kemp, S. High resolution provenance of desert dust deposited on Mt. Elbrus, Caucasus in 2009-2012 using snow pit and firn core records. Cryosphere 2013, 7, 1481-1498. [CrossRef]

28. Middleton, N.J. Dust storms in the Middle East. J. Arid Environ. 1986, 10, 83-96. [CrossRef]

29. Sharif, F.; Alam, K.; Afsar, S. Spatio-temporal distribution of aerosol and cloud properties over Sindh using MODIS satellite data and a HYSPLIT model. Aerosol Air Qual. Res. 2015, 15, 657-672. [CrossRef]

30. Ashpole, I.; Washington, R. An automated dust detection using SEVIRI: A multiyear climatology of summertime dustiness in the central and western Sahara. J. Geophys. Res. Atmos. 2012, 117, D080202. [CrossRef]

(C) 2019 by the authors. Licensee MDPI, Basel, Switzerland. This article is an open access article distributed under the terms and conditions of the Creative Commons Attribution (CC BY) license (http://creativecommons.org/licenses/by/4.0/). 